\title{
Spectral and photophysical properties of phenalenone dyes in aliphatic polyurethane matrix
}

\author{
V.I.Bezrodnyi, M.C.Stratilat ${ }^{*}$, L.F.Kosyanchuk*, \\ A.M.Negriyko, G.V.Klishevich, T.T.Todosiichuk ${ }^{*}$
}

\author{
Institute of Physics, National Academy of Sciences of Ukraine, \\ 46 Nauki Ave., 03680 Kyiv, Ukraine \\ "Institute of Macromolecular Chemistry, \\ National Academy of Sciences of Ukraine, 48 Kharkovskoe Ave., \\ 02160 Kyiv, UkraineReceived January 20, 2015
}

\begin{abstract}
Spectral and photophysical properties of several phenalenone dyes were investigated in dependence on the type of polyurethane polymer matrix. The increase in polarity of the solid-state medium was shown to shift absorption and luminescence to the low energy side. Structural effects of the substituents in the phenalenone chromophore on the Stokes shift value were studied. Photophysical properties of phenalenones were found out to be significantly dependent on polymerization method of the polymer matrices. Considerable growth in photostability of the organic dyes was obtained under their covalent bonding with the polymer chain.
\end{abstract}

Keywords: polyurethane, phenalenone dyes, polarity, photostability, solvation.

Исследованы спектральные и фотофизические свойства серии феналеноновых красителей в зависимости от типа полимерной полиуретановой матрицы. Показано, что увеличение полярности твердотельной среды смещает поглощение и люминесценцию в сторону низких энергий. Изучено структурное влияние заместителей в хромофоре феналенона на величину Стоксова сдвига. Выявлено существенное влияние метода полимеризации полимерной матрицы на фотофизические свойства феналенонов. Получено увеличение фотостабильности органических красителей при их ковалентном связывании с полимерной цепью.

Спектральні та фотофізичні властивості феналенонових барвників в аліфатичній поліуретановій матриці. В.І.Безродний, М.С.Стратілат, Л.Ф.Косянчук, А.М.Негрійко, Г.В.Клішевич, Т.Т.Тодосійчук

Досліджено спектральні та фотофізичні властивості серії феналенонових барвників в залежності від типу полімерної поліуретанової матриці. Показано, що збільшення полярності твердотільного середовища зсуває поглинання і люмінесценцію в сторону низьких енергій. Вивчено структурний вплив замісників у хромофорі феналенону на величину Стоксового зсуву. Виявлено суттєвий вплив методу полімеризації полімерної матриці на фотофізичні властивості феналенонів. Отримано збільшення фотостабільності органічних барвників при їх ковалентному зв'язуванні з полімерним ланцюгом.

\section{Introduction}

In the last few decades, a great interest is observed in the development of dye-doped polymer solid-state lasers. Dye-doped solidstate active laser medium makes it possible to avoid a set of disadvantages assigned with liquid solvents, such as convection, evaporation, toxicity of the solvents, necessity of pumping devices for liquids, and also it provides simplicity in operation. In 
all applications of the dye lasers, photochemical stability of the dyes under irradiation and their long-term preservation under storage remain the main problems. Photobleaching mechanism can vary from one class of dyes to another, and also it is affected by physico-chemical properties of the solvents, the presence of reactive dopants (oxygen, radicals of different types, etc.), and polymerization methods of the polymer matrices. Long-time and efficient generation properties of the laser elements based on organic dyes depend also to a large extent on the initial spectral-luminescent characteristics of the dyes $[1,2]$ and physico-chemical features of the polymer matrices [3-5].

The spectral-luminescent and physical properties of the dyes (conversion efficiency of absorbed energy into luminescence, large Stokes shift, photoresistance, a broad luminescence band) predetermine substantially their use as the dye laser active centers. Aminoderived compounds of phenalenone satisfy these requirements [6-10]. The laser-strong polymer matrices should possess high resistance to the exposure to powerful broadband radiation of pulse lamps and coherent pumping. Acrylate polymers, namely, modified polymethyl methacrylate $[3,5]$ and elastic polyurethane acrylate [1, $6,12]$ have found wide applications as solidstate matrices of the dye laser active media.

The paper [13] describes results on the solvatochromic shift of squaraine dyes in dependence on polarity of the polymer media. Investigations of spectral and photophysical properties of phenalenone dyes depending on the polarity properties of polyurethane polymer matrix are of interest; this is an aim of the present study.

\section{Experimental}

The present work is devoted to investigation on how the polymer matrix based on aliphatic polyurethane (APU) affects the spectral and photophysical properties of phenalenone dyes. These dyes luminesce intensively in alcohol solutions, and generate efficiently in a wavelength range over $600 \mathrm{~nm}$ under the pumping of neodymium laser second harmonic radiation. The properties of four dyes (SYNTHON Chemicals $\mathrm{GmbH}$ ), which structural formula are shown in Fig. 1, have been studied. All the compounds are aminoderived from the 1-phenalenone (perinaphthenone) molecule [10].

Without details of the dye synthesis, one should note, that to obtain a bathochromic

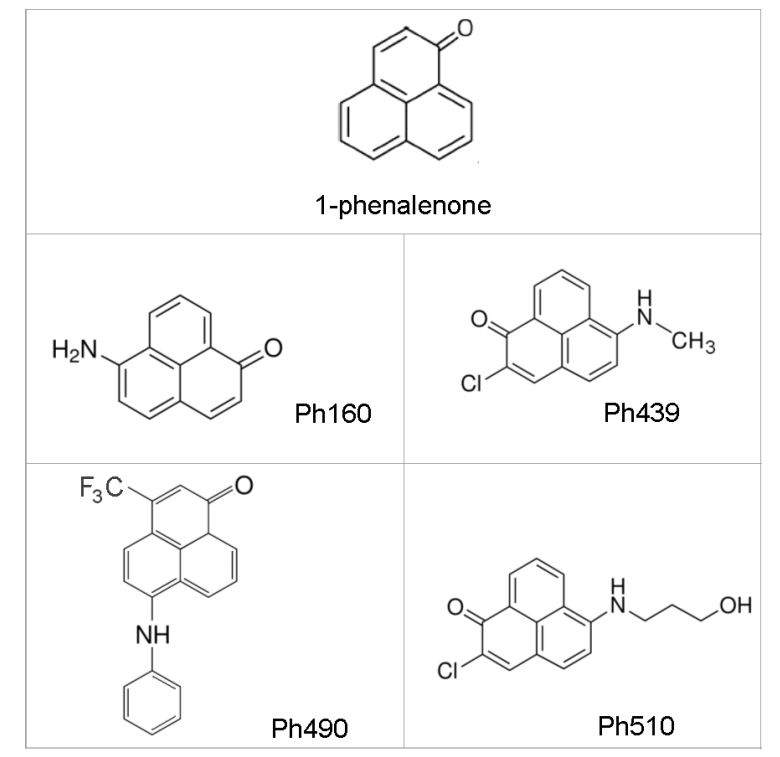

Fig. 1. Structural formulae of phenalenone dyes.

shift towards the region of coherent pumping at $532 \mathrm{~nm}$ and to broaden the spectral region, the initial molecule 1-phenalenone (its absorption maximum in 1,4-dioxane is at $360 \mathrm{~nm}$ [10]) should be doped with different substituents. The Ph160 dye (6-amino-1phenalenone) was produced by inserting of $-\mathrm{NH}_{2}$ amino-group in the position 6. Ph439 (2-chloro-6-(3-methylamino)-1-phenalenone) compound was synthesized by incorporation of chlorine to 1-phenalenone molecule in the position 2 and 3-methylamino group in the 6 one. Similar method was used for Ph510 (2-chloro-6-(3-hydroxypropylamino)-1-phen alenone) and Ph490 (3-fluorinemethyl-6phenylamino-1-phenalenone) dyes.

We have investigated the listed dyes in the polymer matrix based on APU [14-16], compared to the well-studied polyurethane acrylate (PUA) matrix [6, 11, 12]. These polyurethane matrices are similar on their chemical contents, but differ by the production method, which is polycondensation for the APU and radical polymerization for the PUA. Their dielectric constants are significantly different, while their refractive index values are practically the same.

The aliphatic polyurethane matrix was synthesized from the prepolymer, initially obtained on the base of hexamethylene diisocyanate (HMDI), $\mathrm{O}=\mathrm{C}=\mathrm{N}\left(\mathrm{CH}_{2}\right)_{6} \mathrm{~N}=\mathrm{C}=\mathrm{O}$, oligo-diethylene glycol adipate, $\mathrm{OH}-[-$ $\left.\left(\mathrm{CH}_{2} \mathrm{CH}_{2}\right)_{2}-\mathrm{O}-\mathrm{CO}-\left(\mathrm{CH}_{2}\right)_{4}-\mathrm{CO}-\mathrm{O}-\left(\mathrm{CH}_{2} \mathrm{CH}_{2} \mathrm{O}\right)_{2}-\right]_{n}-\mathrm{H}$, of 800 molecular mass, and trimethylolpropane, $\mathrm{H}_{5} \mathrm{C}_{2}-\left(\mathrm{CH}_{2} \mathrm{OH}\right)_{3}$. The method of 
APU production has been described in detail earlier [14-17].

The dye-doped polymer matrices were obtained by inserting of the corresponding dye dissolved in methylene chloride into the reactive mixture on the stage of polyurethane formation. The reaction mixture was vacuumized to remove air bubbles and solvent. The hardening was carried out at $60^{\circ} \mathrm{C}$ during $8 \mathrm{~h}$.

To compare the spectral (absorption, luminescence) and physical (photostability) properties of the dye-doped APU polymer samples, PUA hardened by the radical photopolymerization method of oligourethane acrylate was used; oligourethane acrylate was obtained from oligooxy (propylene glycol) and toluene diisocyanate. The radical polymerization reaction of PUA was fulfilled at a presence of photoinitiator, benzoin isobutyl ether, $\mathrm{C}_{6} \mathrm{H}_{5}-\mathrm{CH}\left[\mathrm{OCH}_{2} \mathrm{CH}\left(\mathrm{CH}_{3}\right)_{2}\right]-\mathrm{CO}-\mathrm{C}_{6} \mathrm{H}_{5}$. The production method for the samples based on PUA is described in $[6,11,12]$.

The triplexes with quartz glass as substrates were constructed for investigations of photostability and the spectral luminescent properties. Thickness of the dye-activated APU and PUA polymer films in these experiments was equal to $300-400 \mu \mathrm{m}$. The dyes were inserted into the polymer matrices at concentration $\sim 4 \cdot 10^{-4} \mathrm{~mol} / 1$. Optical density, $D_{o}$, was a value of about unity in the maximum of basic transition $\left(D_{o}=\right.$ $1.00 \pm 0.05)$.

Absorption spectra of the polymer samples, containing dyes, were recorded on a spectrophotometer VSU-2P, and fluorescence data were collected with a use of a spectrofluorimeter Hitachi MPF-4.

Photochemical experiments were carried out using the integral radiation of ultraviolet and visible regions from an arc mercury ultrahigh pressure lamp DRK-120. Photostability measurements were done by the mentioned lamp irradiation under the light intensity in the sample zone $I \approx 35 \mathrm{~mW} / \mathrm{cm}^{2}$. Ultraviolet and visible radiation of the lamp was mainly applied for the photostability investigations in $S_{0} \rightarrow S_{1}, S_{2}$ transitions. Excitation of the dyes in APU in the $S_{0} \rightarrow S_{2}$ transition is possible due to the high transparency of this polymer in ultraviolet region [9], which UV absorption edge is located at $250 \mathrm{~nm}$, and due to a use of quartz glass for the substrates. Changes in optical density, $D$, of the samples in dependence on a dose of incident light, $E$, were controlled in the maximum of the dye main absorption band by a spectrophotometer VSU-2P.

Effects of the APU and PUA polymer matrices on the dye photostability were also studied under the irradiation only in the basic electron transition $S_{0} \rightarrow S_{1}$, when continuous generation of the neodymium laser second harmonic radiation (532 $\mathrm{nm})$ with diode pumping (MGL532, Changchum New Industries Optoelectronics Tech. Co.) was applied. Irradiation intensity in the sample zone was $I \approx 4.24 \mathrm{~W} / \mathrm{cm}^{2}$. Measurements of the transmission coefficient (and correspondingly, optical density) were carried out with a use of the electron-optical scheme containing photodetectors (photodiodes FD-24K) and voltmeters V7-16A, which provide the high accuracy of the measurements up to $0.5 \%$.

\section{Results and discussion}

The substituents inserted to the initial molecule 1-phenalenone provide efficient absorption in the spectral region, suitable for the neodymium laser second harmonic pumping. Fig. 2 presents normalized dependences of the optical density, $D$, and luminescence intensity, $I$, of phenalenones in the two polymer matrices. All absorption and luminescence bands of the dyes (except Ph160) possess bathochromic shift when changing from PUA to APU, which is caused by positive solvatochromism and associated with increase of the polymer matrix polarity.

According to the quantum-mechanical perturbation theory for the absorption $\left(v_{a}\right)$ and fluorescence $\left(v_{f}\right)$, the Stokes shift of their spectral positions in the liquid media of different dielectric constant, $\varepsilon$, and refractive index, $n$, is proportional as follows [18]:

$$
v_{a}-v_{f} \sim f(\varepsilon, n)+\text { const },
$$

where the medium polarity, $f(\varepsilon, n)$, is determined by the formula:

$$
f(\varepsilon, n)=\frac{2 n^{2}+1}{n^{2}+2}\left[\frac{\varepsilon-1}{\varepsilon+2}-\frac{n^{2}-1}{n^{2}+2}\right] .
$$

Considering formula (2), the polymer matrix polarity is equal to $f_{\mathrm{PUA}}(\varepsilon, n)=0.284$ (at $\varepsilon=4.1$ and $n=1.4871$ ) for PUA, and correspondingly, it is $f_{\mathrm{APU}}(\varepsilon, n)=0.558$ (at $\varepsilon=8.8$ and $n=1.4898$ ) for the APU. The dependence of the spectral shifts, $\Delta v=v_{a}-$ $v_{f}$ shows good correlation with the polarity 

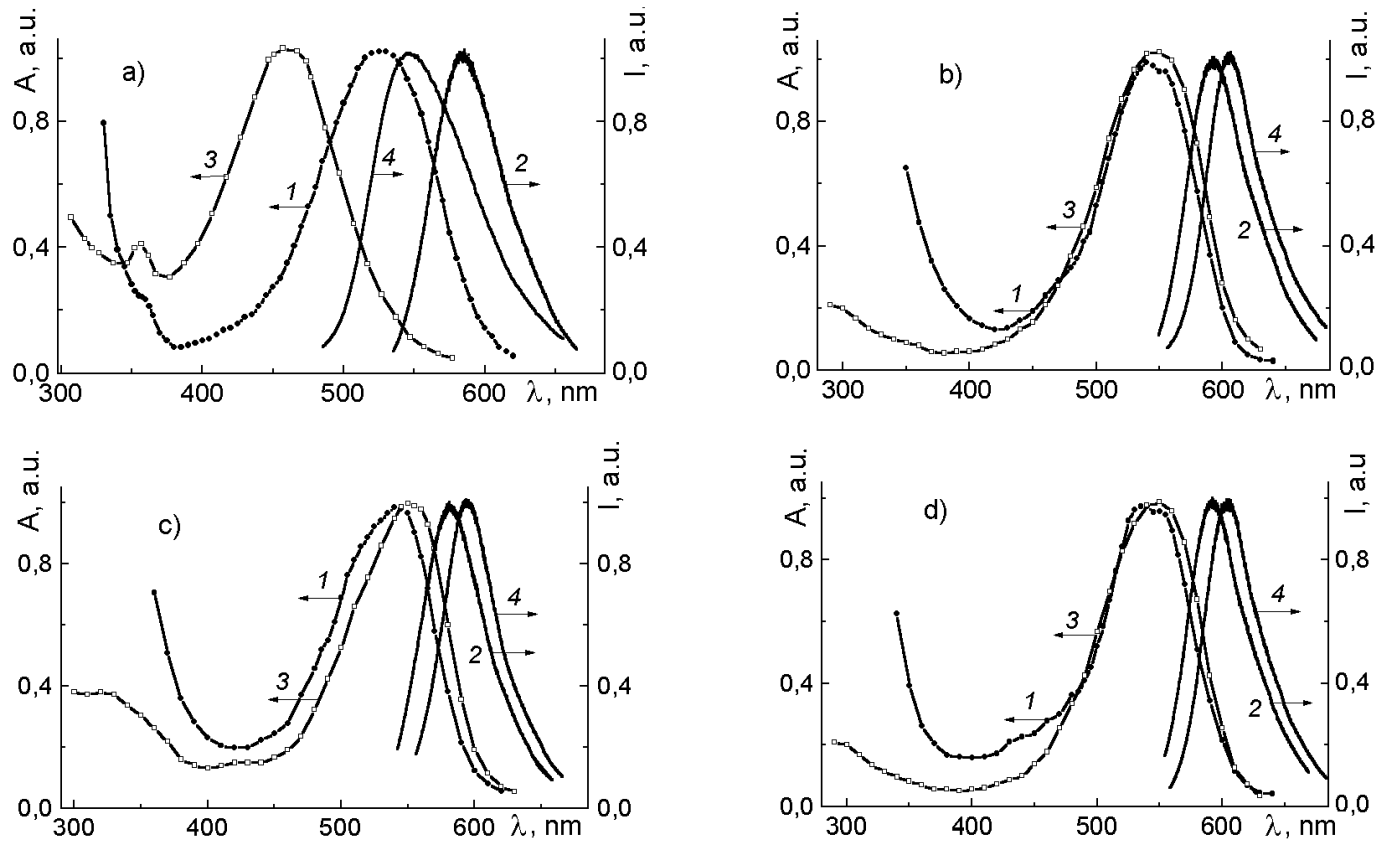

Fig. 2. Absorption $(1,3)$ and luminescence $(2,4)$ spectra of phenalenone dyes: a) - Ph160, b) Ph439, c) - Ph490, d) - Ph510 in PUA $(1,2)$ and APU $(3,4)$.

function, in our case for the polymer media. Values of the Stokes shift determined for each dye are listed in Table 1 for the different polymer matrices.

The APU initial isocyanate component contains functional groups $-\mathrm{N}=\mathrm{C}=\mathrm{O}$, which interact chemically and form covalent bonds with the $-\mathrm{NH}_{2}$ (Ph160 dye) and $-\mathrm{OH}$ (the Ph510) substituents. The chemical reaction of isocyanate with the Ph160 dye occurs by the scheme: ...-N=C=O $+\mathrm{NH}_{2}-\ldots \rightarrow \ldots-\mathrm{NH}-$ $\mathrm{CO}-\mathrm{NH}-\ldots$, generating carbamide as a result. Experiments by infrared spectroscopy methods have proved the presence of the mentioned covalent bond $[16,19]$. The $-\mathrm{NH}_{2}$ substituent in Ph160 dye molecule is a part of the conjugated chain, responsible for absorption and luminescence. Under the chemical bonding, a hydrogen atom of the dye chromophore substituent is transferred to nitrogen atom of isocyanate, and rigid fixation of the dye molecule with the polymer chain occurs. Acidification of the amino-group leads to the blue shift in electronic spectra due to decrease of the nitrogen atom electron-donorship as a result of conjugation between its unshared electron pair and adjacent carbonyl group. This causes changes in the electronic distribution and static dipole moment of the dye molecules, which can be a reason for a large hypsochromic shift for Ph160 in APU, compared with the one in PUA (Fig. 2a).
Table 1. Stokes shift values for the dyes in the polymer matrices

\begin{tabular}{|c|c|c||}
\hline Dye & $\begin{array}{c}\text { Stokes shift in } \\
\text { PUA, } \Delta v, \mathrm{~cm}^{-1}\end{array}$ & $\begin{array}{c}\text { Stokes shift in } \\
\text { APU, } \Delta v, \mathrm{~cm}^{-1}\end{array}$ \\
\hline Ph160 & 1752 & 3440 \\
Ph439 & 1543 & 1709 \\
Ph490 & 1204 & 1346 \\
Ph510 & 1540 & 1672 \\
\hline
\end{tabular}

The Ph510 dye forms also a covalent bond with the polymer chain due to presence of hydroxypropylamine hydroxyl group (Fig. 1). The bonding between hydrogen and nitrogen atoms results in formation of urethane group:

$$
\ldots-\mathrm{N}=\mathrm{C}=\mathrm{O}+\mathrm{HO}-\ldots \rightarrow \ldots-\mathrm{NH}-\mathrm{CO}-\mathrm{O}-\ldots . .
$$

This chemical reaction was also investigated in the present work by means of infrared spectroscopy. To prove this interaction, a model reaction between the Ph510 dye molecules and APU was carried out on a stage of the polymer formation. The dye and HMDI (molecule ratio 1:1) were mixed in dichloroethane and stirred at $60^{\circ} \mathrm{C}$ during $10 \mathrm{~h}$. Fourier transform infrared spectroscopy method was used for the recording of IR-spectra. The spectral data (Fig. 3) were obtained on a spectrometer Bruker IFS-88 in the region of $400-4000 \mathrm{~cm}^{-1}$. For the 


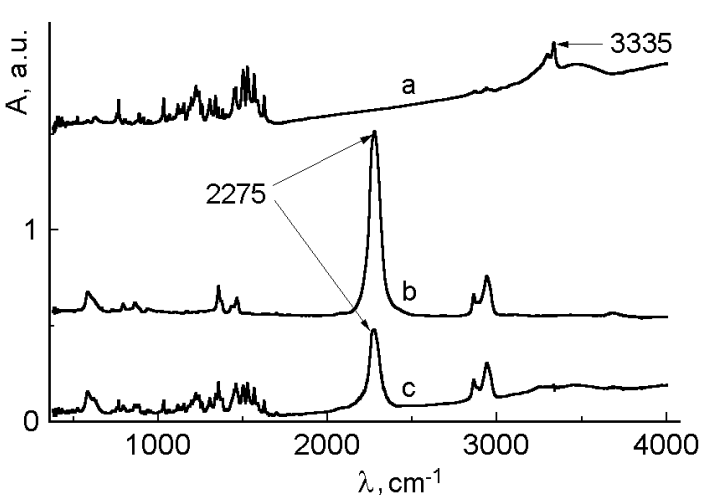

Fig. 3. Infrared spectra of a) Ph510 dye, b) HMDI, c) Ph510 dye with HMDI.

measurements, the Ph510 dye and model reaction product samples were prepared by pressing the substances into the pellets with $\mathrm{KBr}$. The HMDI was thinly layered between $\mathrm{KBr}$ substrates. The HMDI intensive band $v(\mathrm{NCO})$ at $2275 \mathrm{~cm}^{-1}$ (Fig. 3b) decreases two times in the mixture of HMDI and Ph510 (Fig. 3c) as a result of interaction, which is seen from its comparison with the intensity of $\mathrm{CH}$ stretching vibration bands near $2900 \mathrm{~cm}^{-1}$ (Fig. 3c, d). The absorption band of the Ph510 dye hydroxyl group $v(\mathrm{OH})$ at $3335 \mathrm{~cm}^{-1}$ (Fig. 3a) disappears after formation of the covalent bonding (Fig. 3c). Additionally, an indirect evidence of the chemical interactions of Ph510 and Ph160 with polyurethane chain is the results of extraction experiments for the dyedoped APU samples by ethanol. The films remain coloured even after the hours-long extraction process. And the electronic spectrum of ethanol after extraction does not contain any absorption bands of the dyes.

The analysis of the dye Stokes shifts, $\Delta v=$ $v_{a}-v_{f}$, shows that these values are systematically bigger in APU, than in PUA (Table $1)$, since polarity of the first matrix is twice as much high, than the second one. The lesser value of $\Delta v=v_{a}-v_{f}$ for Ph490 dye in APU can be explained by the presence of 6-phenylamino voluminous substituent, which hinders sterically strong solvatochromism of the polymer surrounding on the electron shell of the conjugated chain.

Photophysical properties of the dyes in PUA and APU were studied using two light sources, namely, a mercury lamp DRK-120 and a laser with continuous generation at 532 nm. Fig. 4 (a, b) shows dependences of the optical density on irradiation dose by the mercury lamp, $D(E)$. There is multiple
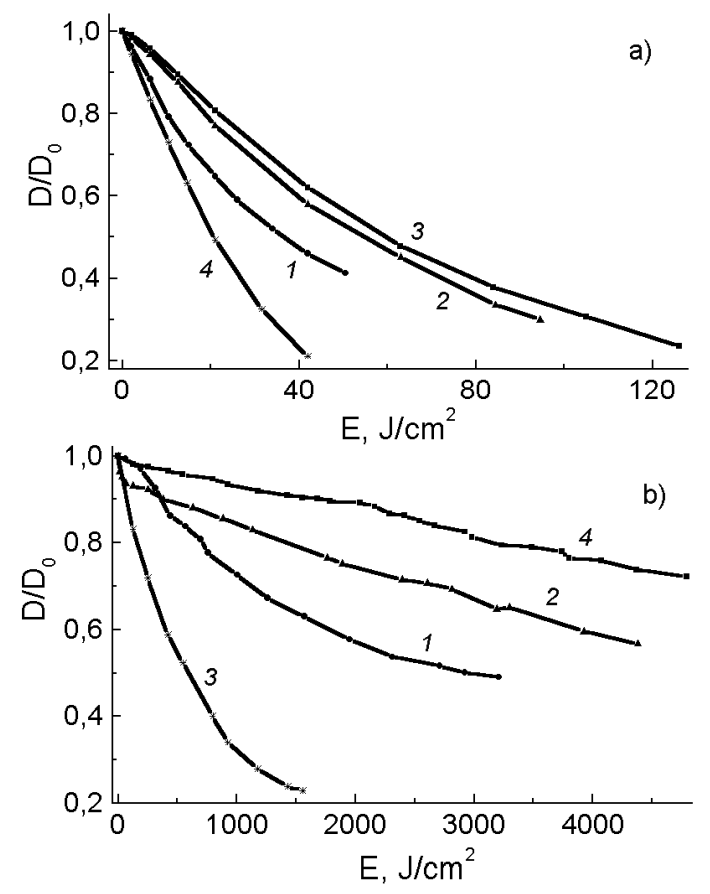

Fig. 4. Kinetic curves of phenalenone dye photobleaching under irradiation by a mercury lamp: a) in PUA, b) in APU (1 Ph160, 2 - Ph439, 3 - Ph490, 4 - Ph510).

increase (two orders in magnitude) observed in photostability of the phenalenone dyes in APU (Fig. 4b), compared to the samples based on PUA (Fig. 4a). Presented results demonstrate significant growth of the dye photostability, when changing from PUA to APU under the irradiation in $S_{0} \rightarrow S_{1}, S_{2}$ transitions.

The results of the experiments in the case of irradiation by the second harmonic continuous generation (532 $\mathrm{nm}$ ) of the neodymium laser only in the electron basic transition $\left(S_{0} \rightarrow S_{1}\right)$ are presented in Fig. 5 (a, b, c, d), where curves (1) concern the PUA matrix, and (2) the ones are for APU, correspondingly. Numerical data for the irradiation dose causing a twofold drop in the initial optical density of the samples under irradiation by the mercury lamp and the laser are listed in Table 2.

The studies on comparison between the two matrices, PUA and APU, indicate a crucial factor in the dye photostability to be a presence in the first medium (or an absence in the second one) of radicals in the polymer. Free radicals formed from the unreacted molecules of polymerization initiator or those ones, appeared in the process of PUA production, favor further activation of the radical reactions under the interaction with light inducing destruction of dye mole- 
V.I.Bezrodnyi et al. / Spectral and photophysical ...

Table 2. Photostability of the dyes in PUA and APU matrices

\begin{tabular}{|c|c|c|c|c|}
\hline \multirow[t]{2}{*}{ Dye } & \multicolumn{2}{|c|}{$\begin{array}{l}\text { The DRK-120 lamp irradiation dose, } \\
\text { caused } D_{o} \text { twofold decrease, } \mathrm{kJ} / \mathrm{cm}^{2}\end{array}$} & \multicolumn{2}{|c|}{$\begin{array}{l}\text { The continuous laser }(\lambda=532 \mathrm{~nm}) \\
\text { irradiation dose, caused } D_{o} \text { twofold } \\
\text { decrease, } \mathrm{kJ} / \mathrm{cm}^{2}\end{array}$} \\
\hline & Dye in PUA & Dye in APU & Dye in PUA & Dye in APU \\
\hline Ph160 & 0.036 & 2.980 & 0.285 & 1.250 \\
\hline Ph439 & 0.055 & 5.570 & 0.550 & 1.480 \\
\hline Ph490 & 0.020 & 0.585 & 0.160 & 0.625 \\
\hline Ph510 & 0.060 & 9.090 & 0.530 & 2.835 \\
\hline
\end{tabular}
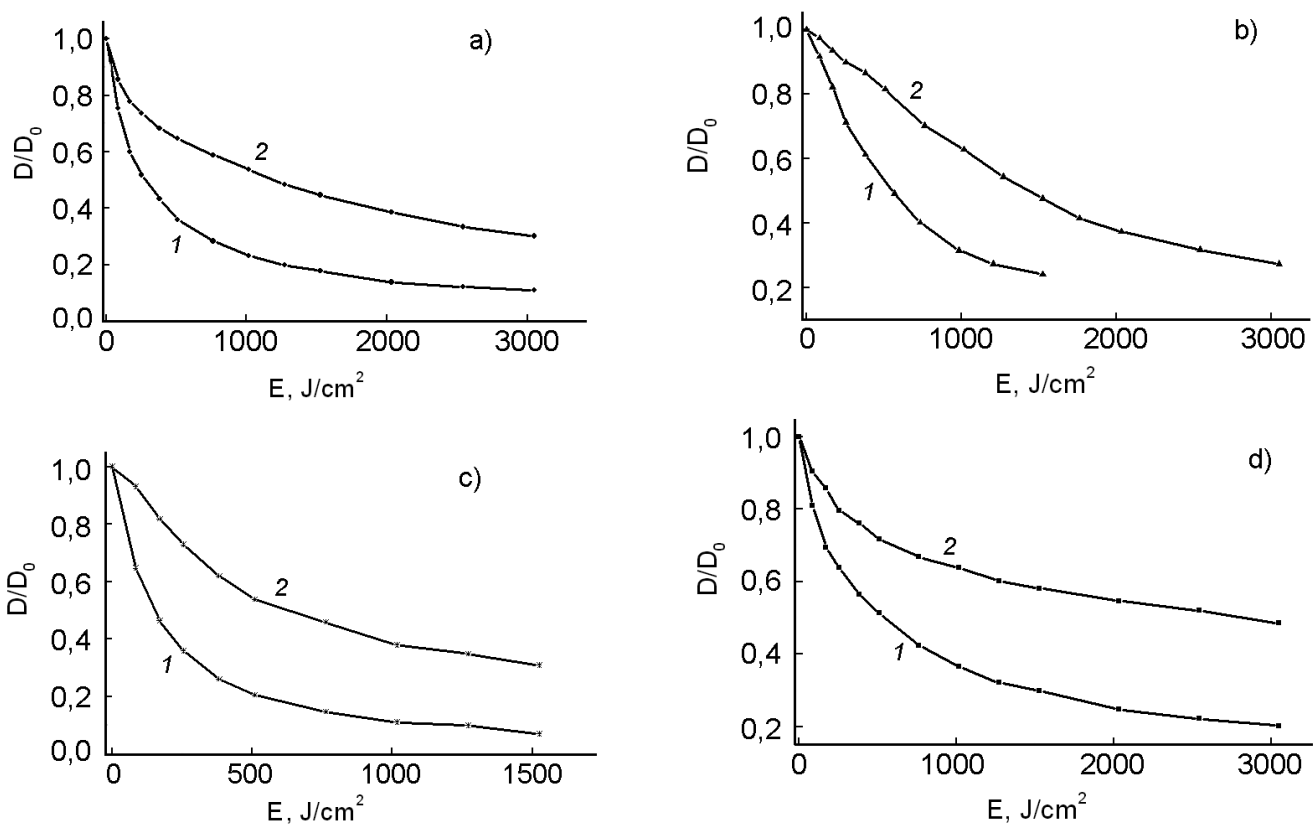

Fig. 5. Kinetic curves of phenalenone dye photobleaching under irradiation by a laser at $532 \mathrm{~nm}$ : a) - Ph160, b) - Ph439, c) - Ph490, d) - Ph510 in 1 - PUA and 2 - APU polymer matrices.

cules. Advantages of APU are caused not only by its production method, but also by its high polarity. This statement was confirmed when the photostability of the dyes in PUA and APU was analyzed under irradiation by the mercury lamp (Fig. 4a,b), as well as by generation at $532 \mathrm{~nm}$ (Fig. 5a, b, c ,d).

Comparing photostability

of phenalenones in APU, one can see that Ph490 dye possesses much stronger destruction, than other dyes under investigation. Despite stronger electron acceptor properties of $-\mathrm{CF}_{3}$ substituent and presence of APU nucleophilic groups, this dye shows the moderate solvation, compared to the higher one for Ph439 and Ph510, which is proved by the difference in their Stokes shifts. The Ph510 is characterized by the highest photostability, caused by the solvate surrounding and covalent bonding with the polymer chain.
Despite the chemical interactions between Ph160 and APU, this dye is worse on photostability even than the "non-linked" Ph439. Under irradiation, 6-amino-1phenalenone, containing an amino-group, forms the long-lived ketyl radical [20], which can interact with other radicals, in particular, the photodecay products of the polymer matrix under UV irradiation.

The absorption spectra of the studied Ph160 and Ph490 dyes contain quite intense absorption in the region of $300-400 \mathrm{~nm}$ (Fig. 2a, c). This allows to conclude that the crucial role in photochemical destruction is played by electron transitions into the higher excited states under UV irradiation. These higher excited states of the dyes can be deactivated nonradiatively in the process of vibrational relaxation and internal conversion through the highly excited vibra- 
tional states of the polymers with formation of the free radicals.

Ph160 dye possesses strong absorption in the spectral regions of 400-500 and 300-360 nm (Fig. 2a), which coincides with intense generation bands of the mercury lamp at 312,404 and $436 \mathrm{~nm}$ [21]. Thus, a conclusion can be made, that photochemical destruction of the Ph160 is mainly ruled by electron transitions in the singlet states $S_{0} \rightarrow S_{2}, S_{3}$ under UV irradiation. So the covalently bonded Ph160 is characterized by lower photostability than the Ph510. Ph439 and Ph510 dyes in APU show small absorption in the spectral region of 300-400 nm (Fig. 2b, d), which is practically not affected by the short-wave part of the mercury lamp generation. Degradation of the Ph490 in APU (Fig. 4a, curve 1) can be also explained partly by the presence of intense absorption in the spectral region at $\sim 300 \mathrm{~nm}$ (Fig. 2c).

The high polarity of $\operatorname{APU}\left(f_{\mathrm{APU}}(\varepsilon, n)=\right.$ 0.558), as compared with the other polymers, causes the efficient solvation of the dye molecules, which affects the photostability in a positive way. One should note, that this value for polymethyl methacrylate, widely used in the dye-doped laser media is $f_{\text {PMMA }}=0.1107$, resulting in the small Stokes shift [1,3-5, 8]. In the case of the Ph490 molecules, auxochrome-6-phenylamino group (Fig. 1) makes steric hindrances for solvation of the conjugated chain increasing the photodegradation under irradiation. The strong solvation of Ph439 and Ph510 dyes which is proved by the large Stokes shift (Table 1) results in their high photostability in APU. Positive influence of the large $\Delta v=v_{a}-v_{f}$ value in the dye-doped active elements is also mentioned by other authors [22].

\section{Conclusion}

To conclude, APU polymer matrix of high polarity increases the Stokes shift in the phenalenone dyes and causes the higher photostability in comparison with radicalcontaining PUA due to absence of free radicals and the efficient solvatochromism. The APU has a potential ability to bond covalently with $-\mathrm{NH}_{2}$ and $-\mathrm{OH}$ substituent groups in the dyes. The effects of the large Stokes shift and covalent bonding on generation characteristics of the active media in the dye lasers on phenalenones in APU will be a matter of our further investigations.

\section{References}

1. E.P.Schafer, Dye Lasers, ed. E.P.Schafer, Springer-Verlag, Berlin (1990).

2. T.G.Pavlopoulos, Prog.Quant.Electron., 26, 193 (2002).

3. D.A.Gromov, K.M.Dyumaev, A.A.Manenkov et al., J.Opt.Soc.Am. B, 2, 1028 (1985).

4. M.D.Rahn, T.A.King, Appl. Opt., 34, 8260 (1995).

5. A.Maslyukov, S.Sokolov, M.Kaivola, S.Popov, Appl.Opt., 34, 1516 (1995).

6. M.V.Bondar, O.V.Przhonskaya, E.A.Tikhonov, Quant. Electron., 19, 1415 (1989).

7. R.T.Kuznetsova, A.A.Shaposhnikov, D.N.Filinov et al., Opt.i Spektr, 95, 447 (2003).

8. S.S.Anufrik, M.F.Koldunov, A.A.Manenkov et al., J.Appl. Spectr., 75, 714 (2008).

9. S.M.Dolotov, M.F.Koldunov, Ya.V.Kravchenko et al., Quant.Electron., 32, 669 (2002).

10. E.Oliveros, S.H.Bossmann, S.Nonell et al., New J.Chem., 1, 85 (1999).

11. V.I.Bezrodnyi, M.V.Bondar, O.V.Przhonskaya, E.A.Tikhonov, Bull.Acad.Sci.USSR Div.Sci. Phys., 54, 1476 (1990).

12. V.P.Yashchuk, O.A.Prygodjuk, Quant.Electron. Optoelectron., 7, 77 (2004).

13. E.Vauthey, J.Voss, C.De Caro, A.Renn, U.Wild, Chem. Phys., 184, 347 (1994).

14. V.I.Bezrodnyi, M.S.Stratilat, L.F.Kosyanchuk et al., Rep. Nat. Acad. Sci. Ukraine, 7, 108 (2013).

15. V.I.Bezrodnyi, M.S.Stratilat, L.F.Kosyanchuk et al., J.Polym. Res., 20, 246 (2013).

16. L.Kosyanchuk, T.Bezrodna, M.Stratilat et al., J. Polym.Res., 21, 564 (2014).

17. Pat.t Ukraine 107024 (2014).

18. M.M.Husaina, R.Sindhua, H.C.Tandon, Europ. J.Chem., 3, 5 (2012).

19. M.S.Stratilat, L.F.Kosyanchuk, T.T.Todosiichuk, Polym.J., 36, 245 (2014).

20. N.A.Kuznezova, O.L.Kaliya, N.T.Ioffe, S.L.Solodar, Zh.Obshch.Khimii, $\mathbf{5 5 ,} 389$ (1984).

21. J.F.Rabek, Experimental Methods in Photochemistry and Photophysics, M. Mir, (1982) [in Russian].

22. V.V.Maslov, Functional Materials, 19, 226 (2012). 